\title{
Editorial
}

\section{Structural Health Monitoring-Oriented Data Mining, Feature Extraction, and Condition Assessment}

\author{
Ting-Hua Yi, ${ }^{1}$ Stathis C. Stiros, ${ }^{2}$ Xiao-Wei Ye, ${ }^{3}$ and Jun $\mathrm{Li}^{4}$ \\ ${ }^{1}$ School of Civil Engineering, Dalian University of Technology, Dalian 116023, China \\ ${ }^{2}$ Department of Civil Engineering, Patras University, 26500 Patras, Greece \\ ${ }^{3}$ Department of Civil Engineering, Zhejiang University, Hangzhou 310058, China \\ ${ }^{4}$ School of Civil and Resource Engineering, University of Western Australia, Perth, WA 6009, Australia \\ Correspondence should be addressed to Xiao-Wei Ye; cexwye@zju.edu.cn
}

Received 13 February 2014; Accepted 13 February 2014; Published 17 March 2014

Copyright (C) 2014 Ting-Hua Yi et al. This is an open access article distributed under the Creative Commons Attribution License, which permits unrestricted use, distribution, and reproduction in any medium, provided the original work is properly cited.

Structural health monitoring (SHM) is the usage of modern sensing technologies, communication algorithms, and advanced data mining and management systems to monitor the operational environments and loadings as well as the structural responses in real time, to effectively evaluate the structural health condition and safety performance and to instruct the daily structural inspection and maintenance, which is a multidiscipline and cutting-edge research field in civil engineering [1-3]. In the past several decades, a great amount of long-term SHM systems have been designed and implemented worldwide on civil engineering structures such as large-scale bridges and high-rise buildings [4]. With these SHM systems, a vast ocean of information relevant to the structural responses and behavior can be continuously obtained in real time. The measurement data are valuable in detecting structural anomalies and damage at an early stage to ensure operational safety and in providing authentic information for timely assessment after disasters and extreme events.

A critical issue of great concern is how to extract the features inherent in the monitoring data for structural performance assessment targeting life-cycle safety, reliability, durability, and sustainability. Therefore, intelligent computational methodologies and approaches, such as artificial neural networks, fuzzy logic systems, and genetic algorithms, are always desired. Numerous investigators worldwide were invited to contribute their original papers and review articles on the theme of this special issue.
A total of 44 technical papers are received and 25 out of them are finally accepted for publication in this special issue. The first seven papers address novel sensing technologies in SHM. The paper "Recent developments on wireless sensor networks technology for bridge health monitoring" by G.D. Zhou and T.-H. Yi summarizes the recent technology developments in the field of bridge health monitoring with the use of the wireless sensor networks. The paper "Review of physical based monitoring techniques for condition assessment of corrosion in reinforced concrete" by Y. Lei and Z.-P. Zheng reviews the physical based steel corrosion monitoring techniques developed in the last decade. In the paper "Analysis on factors affecting the self-repair capability of SMA wire concrete beam" by L. Sun et al., the authors investigate the influential factors on the self-repair capability of shape memory alloy wire concrete beam. The paper "Analysis of precursors prior to rock burst in granite tunnel using acoustic emission and far infrared monitoring" by Z. Liang et al. investigates the progressive failure of a rock tunnel model by use of the acoustic emission and far-infrared techniques. The paper "A three-dimensional model of the effective electromechanical impedance for an embedded PZT transducer" by C. Zuo et al. proposes a three-dimensional model for the embedded PZT sensor by considering the interaction between the PZT and the host structure. The paper "GPS and InSAR time series analysis: deformation monitoring application in a hydraulic engineering resettlement zone, Southwest China" by R. Xiao and X. He presents the application of the GPS and InSAR for 
deformation measurement in hydraulic engineering. In the paper "FBG-based creep analysis of GFRP materials embedded in concrete" by G.-W. Li et al., the authors investigate the creep interaction behavior between prestressed GFRP bar and concrete using the fiber Bragg grating sensors.

The subsequent four papers focus on the research pertaining on structural condition assessment. The paper "A state-ofthe-art review on fatigue life assessment of steel bridges" by X. $\mathrm{W}$. Ye et al. presents a summary on the development history and current status of fatigue condition assessment of steel bridges. The paper "Condition assessment on thermal effects of a suspension bridge based on SHM oriented model and data" by $\mathrm{B}$. Chen et al. carries out the condition assessment on temperature distribution and thermal effects of a long span suspension bridge by use with both the numerical simulation and monitoring data. In the paper "Statistical estimation of changes in the dominant frequencies of structures in long noisy series of monitoring data" by F. Moschas and E. Steirou, the authors adapt a statistical approach for identification of the dominant frequencies of structures targeting structural health condition assessment. The paper "Safety monitoring index of high concrete gravity dam based on failure mechanism of instability" by S. Wang et al. presents the establishment process of safety monitoring index for high concrete gravity dams based on the failure mechanism of instability.

The next four papers address the research on structural damage detection and model updating. The paper " $A$ time-domain structural damage detection method based on improved multiparticle swarm coevolution optimization algorithm" by S.-F. Jiang et al. proposes an improved multiparticle swarm coevolution optimization method for structural damage localization and quantification. The paper "Innovative data fusion enabled structural health monitoring approach" by $\mathrm{X}$. Zhao et al. proposes a data fusion enabled method based on the Dempster-Shafer evidence theory for structural damage detection. In the paper "Structural damage identification based on the minimum system realization and sensitivity analysis" by W. R. Li et al., the authors develop a new method for damage detection by combing the minimum system realization and sensitivity analysis. The paper "PZT-based detection of compactness of concrete in concrete filled steel tube using time reversal method" by S. Yan et al. develops a wavebased smart sensing system for concrete compactness detection by use with the piezoceramic-based smart aggregates.

The following four papers present the achievements on system and parameter identification. The paper "Construction of stiffness and flexibility for substructure-based model updating" by S. Weng et al. conducts the research on the substructuring methods by taking a deeper look at the analysis of a free-free substructure. The paper "Intelligent platform for model updating in a structural health monitoring system" by D. Dan et al. develops an automated smart software platform to improve the time-consuming and laborious process in model updating. In the paper "Complete inverse method using ant colony optimization algorithm for structural parameters and excitation identification from output only measurements" by
J. Chen et al., the authors integrate the ant colony optimization algorithm with the complete inverse method for simultaneous identification of unknown structural parameters and input time histories using output-only measurements. The paper "Structural system identification with extended Kalman filter and orthogonal decomposition of excitation" by Y. Ding et al. proposes a system identification method in the time domain for simultaneous evaluation of structural parameters and external excitations.

The remaining six papers in this special issue are on the topics of field and laboratory measurements. The paper "An improved negative pressure wave method for natural gas pipeline leak location using FBG based strain sensor and wavelet transform" by Q. Hou et al. develops an FBG based strain sensor for measurement and detection of the negative pressure wave signal produced by leakage in pipelines. The paper "Real-time dry beach length monitoring for tailings dams based on visual measurement" by $\mathrm{J}$. $\mathrm{Hu}$ et al. presents a method for dry beach length measurement through the ordinary camera and the effectiveness of which has been verified by the experimental study. The paper "Field measurement of wind speeds and wind-induced responses atop the Shanghai World Financial Center under normal climate conditions" by Y. Quan et al. presents the field measurement data of wind velocities and wind-induced accelerations at the top of the Shanghai World Financial Center under normal climate conditions. In the paper "Slope stability analysis based on measured strains along soil nails using FBG sensing technology" by H.-F. Pei et al., the authors evaluate the safety factor of a slope by measurement of the strains on the soil nails with the fiber Bragg grating sensors. The paper "Experimental study of aerodynamic damping of typical tall buildings" by $\mathrm{P}$. Huang et al. conducts an experimental study on aerodynamic damping measurements by use of the aeroelastic models of tall buildings with typical cross-sections in a wind tunnel. The paper "A method of data recovery based on compressive sensing in wireless structural health monitoring" by S. Ji et al. proposes a method of recovering lost data in wireless sensor networks based on compressive sensing and validates the proposed method through measurements. Without a doubt, the papers reflect the state-of-the-art researches and developments of this subject.

\section{Acknowledgments}

The guest editors would like to express their sincere appreciation to all the authors for contributing their latest research work to this special issue. We are grateful to the reviewers for their constructive and insightful comments. This meaningful work was jointly supported by the National Natural Science Foundation of China (Grants nos. 51121005, 51222806, and 51327003) and the Specialized Research Fund for the Doctoral Program of Higher Education (Grant no. 20130041110031).

Ting-Hua Yi

Stathis C. Stiros

Xiao-Wei Ye

Jun $\mathrm{Li}$ 


\section{References}

[1] T.-H. Yi, H.-N. Li, and M. Gu, "Optimal sensor placement for structural health monitoring based on multiple optimization strategies," The Structural Design of Tall and Special Buildings, vol. 20, no. 7, pp. 881-900, 2011.

[2] T. H. Yi, H. N. Li, and X. D. Zhang, "Sensor placement on Canton Tower for health monitoring using asynchronousclimbing monkey algorithm," Smart Materials and Structures, vol. 21, no. 12, Article ID 125023, 12 pages, 2012.

[3] T.-H. Yi, H.-N. Li, and M. Gu, "Characterization and extraction of global positioning system multipath signals using an improved particle-filtering algorithm," Measurement Science and Technology, vol. 22, no. 7, Article ID 075101, 11 pages, 2011.

[4] T.-H. Yi, H.-N. Li, and M. Gu, "Recent research and applications of GPS-based monitoring technology for high-rise structures," Structural Control and Health Monitoring, vol. 20, no. 5, pp. 649670, 2013. 


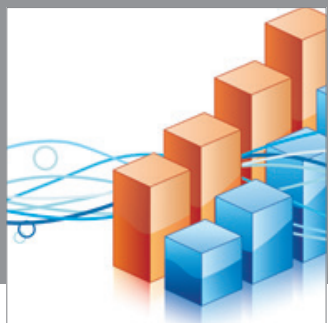

Advances in

Operations Research

mansans

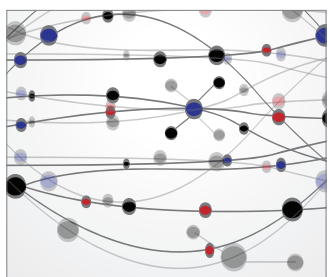

The Scientific World Journal
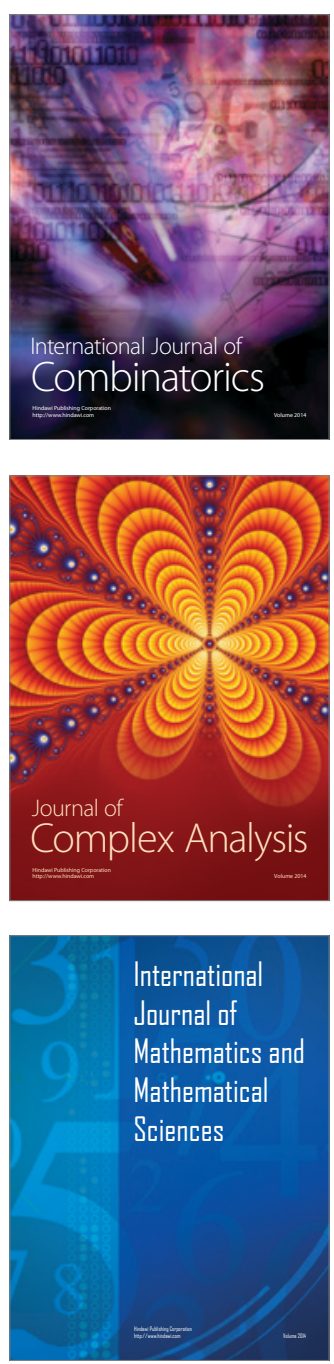
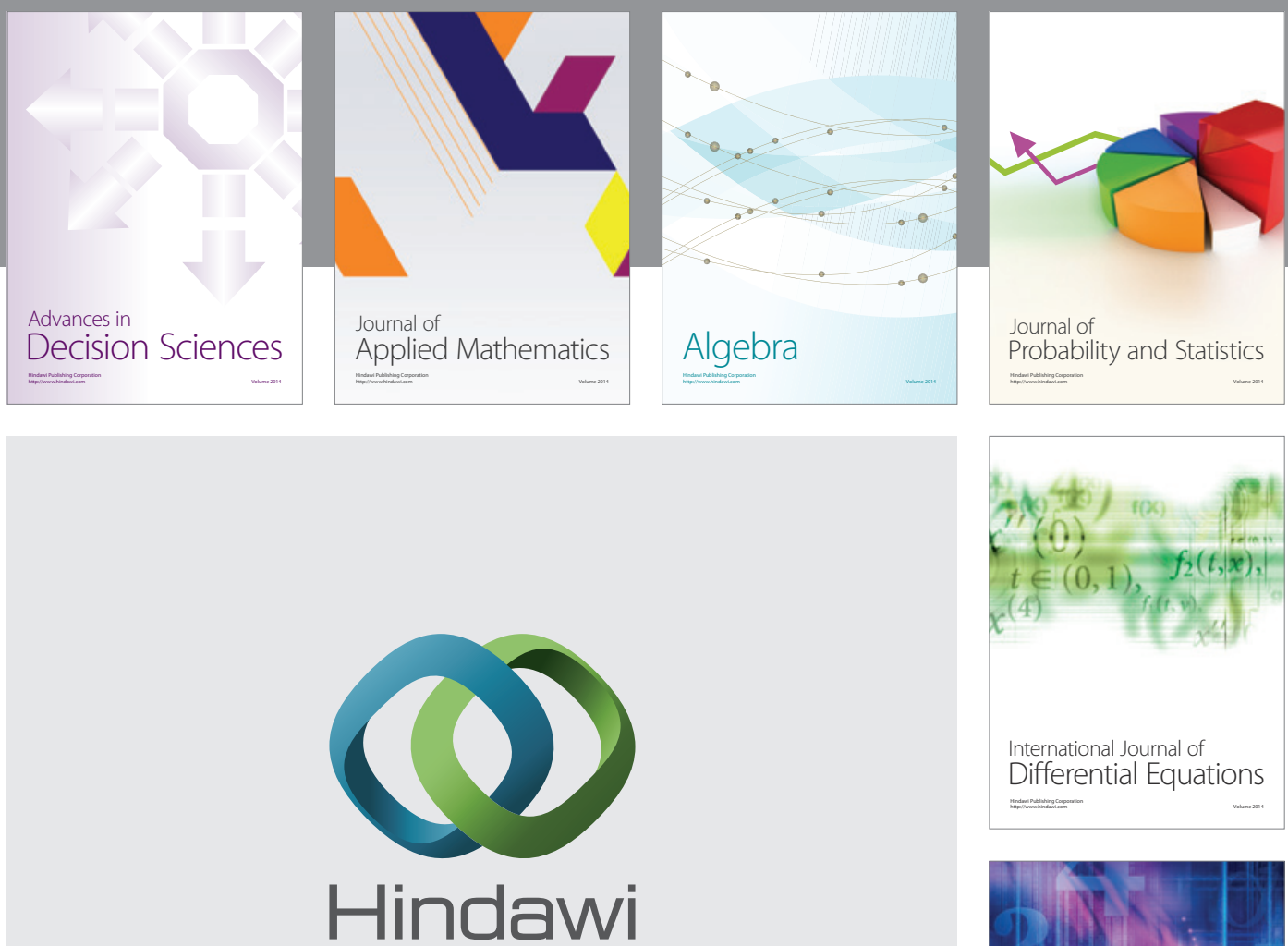

Submit your manuscripts at http://www.hindawi.com
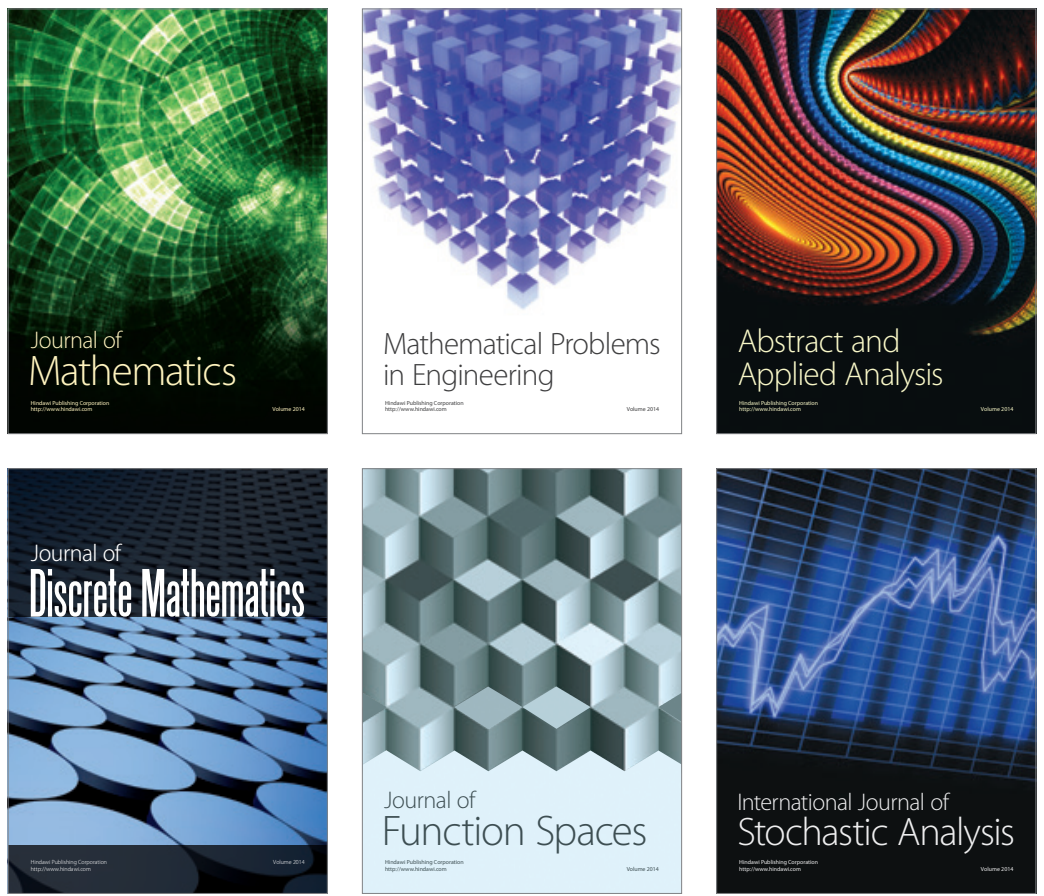

Journal of

Function Spaces

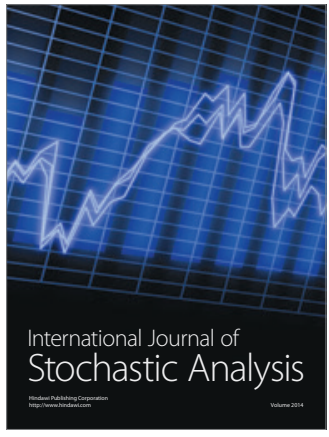

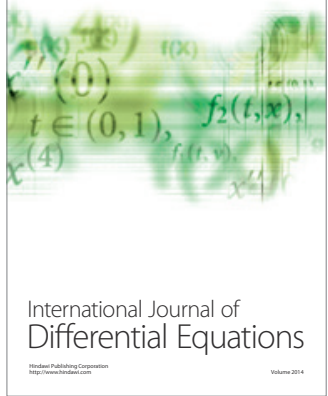
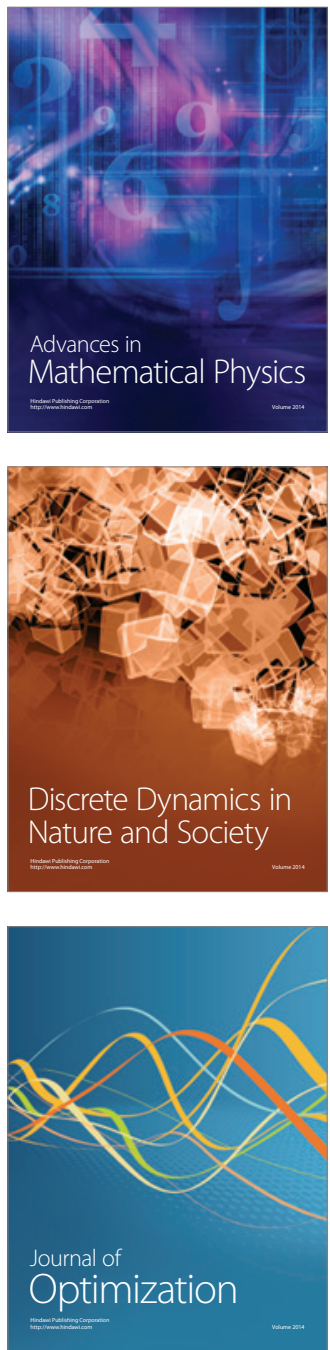